\title{
Letters
}

\section{Many climate change scientists do not agree that global warming is happening}

EDITOR-The apocalyptic tone that Smith adopted in relation to the environment bears little relation to reality. ${ }^{1}$ In his editorial Smith asserts, "virtually all scientists agree that global warming is happening." Global warming is now joining the list of "what everyone knows."

Whether most scientists outside climatology believe that global warming is happening is less relevant than whether the climatologists do. A letter signed by over 50 leading members of the American Meteorological Society warned about the policies promoted by environmental pressure groups. "The policy initiatives derive from highly uncertain scientific theories. They are based on the unsupported assumption that catastrophic global warming follows from the burning of fossil fuel and requires immediate action. We do not agree."' Those who have signed the letter represent the overwhelming majority of climate change scientists in the United States, of whom there are about 60. McMichael and Haines

\footnotetext{
Advice to authors

We receive more letters than we can publish:we can currently accept only about one third. We prefer short letters that relate to articles published within the past four weeks. We also publish some "out of the blue" letters, which usually relate to matters of public policy.

When deciding which letters to publish we favour originality, assertions supported by data or by citation, and a clear prose style. Letters should have fewer than 400 words (please give a word count) and no more than five references (including one to the BMJ article to which they relate); references should be in the Vancouver style. We welcome pictures.

Letters, whether typed or sent by email, should give each author's current appointment and full address. Letters sent by email should give a telephone and fax number when possible. We encourage you to declare any conflict of interest. Please send a stamped addressed envelope if you would like to know whether your letter has been accepted or rejected.

We may post some letters submitted to us on the world wide web before we decide on publication in the paper version. We will assume that correspondents consent to this unless they specifically say no.

Letters will be edited and may be shortened.
}

quote the 1995 report of the Intergovernmental Panel on Climate Change (IPCC), which is widely believed to "prove" that climate change induced by humans has occurred. ${ }^{3}$ The original draft document did not say this. What happened was that the policymakers' summary (which became the "take home message" for politicians) altered the conclusions of the scientists. This led Dr Frederick Seitz, former head of the United States National Academy of Sciences, to write, "In more than sixty years as a member of the American scientific community ... I have never witnessed a more disturbing corruption of the peer-review process than the events that led to this IPCC report."

Policymaking should be guided by proved fact, not speculation. Most members of the Intergovernmental Panel on Climate Change believe that current climate models do not accurately portray the atmosphereocean system. Measurements made by means of satellites show no global warming but a cooling of $0.13^{\circ} \mathrm{C}$ between 1979 and $1994 .^{5}$ Furthermore, since the theory of global warming assumes maximum warming at the poles, why have average temperatures in the Arctic dropped by $0.88^{\circ} \mathrm{C}$ over the past 50 years?

Gregory Gardner Locum general practitioner 64 Chelworth Road, Birmingham B38 0AE

1 Smith R. Climate change: decision time in Kyoto. BMJ 1997;315:1326. (22 November.)

2 Michaels P. Conspiracy, consensus or correlation? What scientists think about the 'popular vision' of global warming. World Climate Review 1993;1:11

3 McMichael AJ, Haines A. Global climate change: the potential effects on health. BMJ 1997;315:805-9.

4 Seitz F. Major deception on global warning. Wall Street Journal 1996 June 12;section A:16(col 3).

5 Balling RC. Global warming: messy models, decent data and pointless policy. In: Bailey R, ed. The true state of the planet. New York: Free Press, 1995:83-107.

\section{$B M J$ is second most popular journal among surgeons}

EDITOR-The Editor's choice of 27 November expressed concern about the readership of the $B M J$ among surgeons. A recent survey of the candidates who passed the intercollegiate specialty examination in general surgery in 1997, undertaken by the Intercollegiate Board in General Surgery, identified the $B M J$ as the second most regularly read journal. The journal that was most commonly read was the British Journal of Surgery.
Candidates may have been reading the $B M J$ in anticipation of passing the examination and being in a position to apply for job advertisements for consultant surgeons. The survey does, however, indicate that the $B M J$ has a considerable readership among specialist registrars in general surgery. This readership would enjoy increased numbers of general surgical articles in addition to the breadth of material already presented.

D A D Macleod Chairman

Intercollegiate Board in General Surgery, Edinburgh EH8 9DR

\section{Preventing $\mathrm{RhD}$ haemolytic disease of the newborn}

\section{RhD negative women who have intrauterine death may need anti-D immunoglobulin}

EDITOR-Mayne et al reported evidence of benefit from routine antenatal administration of anti-D immunoglobulin to primigravid women who are $\mathrm{RhD}$ negative. ${ }^{1}$ It has been proposed that this policy be adopted nationwide. I would like to suggest another modification to the current guidelines for $\mathrm{RhD}$ negative women who experience an intrauterine death.

Isoimmunisation is a maternal immune response to the passage of fetal red cells into the maternal circulation. This occurs spontaneously in the antenatal period. Many antenatal transplacental haemorrhages pass unrecognised clinically, but large transplacental haemorrhage may cause fetal death. ${ }^{2}$ Even large fetal bleeds are generally pain free, and the woman usually presents with absence of fetal movement alone, the diagnosis not becoming apparent until the result of a Kleihauer test (for fetal cells in the maternal circulation) is known.

Currently, there is no specific advice for the care of $\mathrm{RhD}$ negative women with an intrauterine death, ${ }^{3}$ and many if not all maternity units seem to manage them identically to $\mathrm{RhD}$ negative women in normal labour; anti-D immunoglobulin is given after delivery (within 72 hours for optimal effect). Women with an intrauterine death often present 24 hours or more after fetal movement has stopped, and the fetus may not be delivered for 48 hours, particularly as the mother often returns home before induction of labour. Given this, the delivery may not take place until more than 72 hours after any lethal transplacental haemorrhage. It seems logical, therefore, that all nonsensitised $\mathrm{RhD}$ negative women presenting 
with an intrauterine death should have a Kleihauer test shortly after diagnosis is confirmed with scanning and that this is followed immediately by an injection of anti-D immunoglobulin. The result of the test should be obtained reasonably quickly, and further doses of anti-D immunoglobulin can then be given if the result indicates that the first dose is insufficient.

Transplacental haemorrhage associated with intrauterine death is a rare cause of sensitisation to the $\mathrm{RhD}$ antigen. This alteration to current practice would have only a small impact on the number of women who become sensitised to the $\mathrm{RhD}$ antigen. However, it is particularly important to act promptly in women with an intrauterine death because any transplacental haemorrhage causing fetal death would be large and the chance of sensitisation is greater. And, of course, the woman has already suffered one obstetric catastrophe.

Robert Fox Consultant obstetrician

Taunton and Somerset Hospital, Taunton TA1 5DA

1 Mayne S, Parker JH, Harden TA, Dodds SD, Beale JA. Rate of $\mathrm{RhD}$ sensitisation before and after implementation of a of RhD sensitisation before and after implementation of a community based antenatal piop

2 Weiner CP. Fetal death. In: James DK, Steer PJ, Weiner CP, Gonik B, eds. High risk pregnancy: management options. London: Saunders, 1994

3 National Blood Transfusion Service Immunoglobulin Working Party. Recommendations for the use of anti-D immunoglobulin. Prescribers'J 1991;30:137-45.

4 Bowman JM. Rh immune disease: diagnosis, managemen and prevention. In: Droegemueller W, Sciarra JJ, eds Obstetrics and Gynaecology. Vol 3. Philadelphia: Lippincott, 1991

\section{Guidelines are not followed in many cases}

EDITOR-Routine antenatal prophylaxis against rhesus alloimmunisation from silent fetomaternal haemorrhage in first pregnancies reduces maternal sensitisation fourfold provided that it is combined with appropriate application of the guidelines for using anti-D immunoglobulin to cover events during pregnancy and after delivery. ${ }^{1}$ The fact that Mayne et al achieved almost 100\% cover within two years reflects considerable organisation and cooperation by all involved. The authors' paper was optimistic and forward looking, and its subtext was that increasing uptake of routine prophylaxis increases awareness of the need to use anti-D immunoglobulin in antepartum haemorrhage. It is this aspect of education and motivation that is particularly important in the prevention of rhesus disease.

An audit of 922 rhesus negative women in Mersey showed that potentially avoidable alloimmunisation arose from failure to observe the guidelines in 39\% of cases. ${ }^{2}$ Bleeding after the first trimester was treated with anti-D immunoglobulin in 141 of 171 cases, but in 25 women who bled after 20 weeks' gestation only 250 IU was given, rather than the recommended $500 \mathrm{IU}$. Also, abdominal trauma was not realised to be an indication for anti-D immunoglobulin in 19 of 24 cases.

The need for continuing education of all health professionals who care for pregnant women was shown by this and by misinterpretation of Kleihauer tests, a negative result frequently being wrongly interpreted to mean that prophylaxis was not necessary. Positive results were also misinterpreted. Among 14 women with a fetomaternal haemorrhage greater than $4 \mathrm{ml}$ the additional dose of anti-D immunoglobulin indicated was not given in five. Misunderstanding of the rationale behind postnatal prophylaxis led to this being omitted in five women who had been given anti-D immunoglobulin late in pregnancy to cover antepartum haemorrhage because it was thought that this also covered labour and delivery.

The current guidelines can be made effective by audit of their use, and the introduction of routine prophylaxis will reduce rhesus disease. Since a shortage of anti-D immunoglobulin makes widespread application of routine antenatal prophylaxis unlikely until the 21 st century, the proper use of updated guidelines with frequent reminders and education of those entering obstetric care is still the way forward. This should be extended to include those in accident and emergency departments and all other healthcare professionals required to treat pregnant women

Iain R McFadyen Senior research fellow Department of Obstetrics and Gynaecology, Women's Hospital, Liverpool L8 7SS

Vanessa J Martlew Consultant haematologist Helen L Howard Clinical assistant in transfusion medicine

National Blood Service, Mersey and North Wales Centre, Liverpool L7 8TW

Cyril A Clarke Emeritus professor of medicine Department of Biological Sciences, University of Liverpool, PO Box 147, Liverpool L69 3BX

1 Mayne S, Parker JH, Harden TA, Dodds SD, Beale JA. Rate of $\mathrm{RhD}$ sensitisation before and after implementation of community based antenatal prophylaxis programme. $B M$ 1997;315:1588. (13 December.)

2 Howard HL, Martlew VJ, McFadyen IR, Clarke CA. Preventing rhesus(D) haemolytic disease of the newborn by giving anti-D immunoglobulin: are the guidelines bein adequately followed ? Br J Obstet Gynaecol 1997;104:34-41.

\section{Women should be counselled about source of anti-D immunoglobulin}

EDITOR-Van Dijk's editorial on preventing RhD haemolytic disease of the newborn and a consensus conference on anti-D prophylaxis last year clarify the need for continued reliance on donors' blood to prevent rhesus isoimmunisation. ${ }^{12} \mathrm{I}$ am concerned about the lack of consumer involvement in and awareness of the programme and the proposed extension to the antenatal period for women without obvious sensitising stimuli.

My concern led to an ad hoc survey of women who had received anti-D immunoglobulin in the past and of rhesus negative antenatal women who were scheduled to receive anti-D immunoglobulin if their neonates were detected to be rhesus positive. None of these 12 women knew that anti-D immunoglobulin was a blood product. They had presumed this to be either synthetic or derived from some other natural source. I wonder whether all healthcare givers involved in prescribing and giving the immunoglobulin realise that it is prepared from paid donors' blood.
It is imperative that counselling of pregnant women about rhesus isoimmunisation should include telling them about the source of anti-D immunoglobulin and the small possibility of acquiring bloodborne infections after such injection. This information is vital, because introduction of monoclonal anti-D immunoglobulin is not imminent.

Arabinda Saha Consultant obstetrician and

gynaecologist

North East Lincolnshire NHS Trust, Grimsby

DN33 2BA

1 Van Dijk B. Preventing RhD haemolytic disease of the newborn. BMJ 1997;315:1480-1. (6 December.)

2 Consensus statement from the Roval College of Physicians

of Edinburgh/Royal College of Obstetricians and Gynae-

cologists consensus conference on anti-D prophylaxis

7 and 8 April 1997. Transfus Med 1997;7:1434.

\section{New recommendations must be} explained to GPs and midwives

EDITOR-The revised guidelines on giving anti-D immunoglobulin for $\mathrm{RhD}$ prophylaxis were outlined by van Dijk in his editorial and came from a consensus conference held in Edinburgh in April 1997. ${ }^{1}$ It was agreed that compliance with existing guidelines about the use of anti-D immunoglobulin must be improved to reduce the number of isoimmunised women further. Failure is certainly associated with a lack of information in primary care. Unfortunately, the previous guidelines in 1991 were given no publicity and as a result the information never reached general practitioners and midwives. How do our expert advisers intend informing general practitioners and midwives this time about their recommendations to give anti-D immunoglobulin in the last trimester of pregnancy?

We urgently need a fresh approach by the blood transfusion experts to educate all those who care for pregnant women, especially now that there is additional advice about antenatal prophylaxis. Women will need to understand why some of them (those who are $\mathrm{RhD}$ negative) will require antenatal anti-D immunoglobulin and others (those who are $\mathrm{RhD}$ positive) will not.

We spoke at the annual scientific meeting of the British Blood Transfusion Society in Warwick in September 1997 about the current lack of information and the need to involve women in their own care. We expressed the view that a multidisciplinary working party, including representatives from Royal College of General Practitioners and Royal College of Midwives, should be set up urgently to recommend how to explain the new recommendations. Unfortunately, nothing has happened. We support the advice to give anti-D immunoglobulin during the third trimester of pregnancy, but if there is no consultation and collaboration with primary care and midwifery services the potential benefits of the new recommendations could be lost once again.

Christopher Everett General practitioner Alton Health Centre, Alton, Hampshire GU34 2QX Julie Wray Research fellow-midwife

Royal College of Obstetricians and Gynaecologists Audit Unit, St Mary's Hospital, Manchester M13 0JH

1 Van Dijk B. Preventing RhD haemolytic disease of the newborn. BMJ 1997;315:1480-1. (6 December.) 


\section{Medline and Embase complement each other in literature searches}

EDITOR-Greenhalgh briefly mentions some important differences between the Medline and Embase databases. ${ }^{1}$ To compare the usefulness of the databases in the drug information setting we carried out a prospective study of all requests for drug information that required a literature search during July and August 1996. For each inquiry both databases were searched back to 1992 with current CD ROMs. Standard search strategies were used, based on indexed subject headings and textwords. Relevant articles were selected on the basis of the information in the abstract title or subject headings, or both. When an article seemed to be unique to a database this was verified by cross checking in the other database, using an author or journal name search.

For 11 of 32 questions no relevant information was retrieved by either database, leaving 21 questions for comparison. The same articles were retrieved by both databases for only four questions. Embase retrieved articles that were unique to that database for 14 questions, while Medline retrieved unique articles for two questions. For one question both databases retrieved a unique article.

Embase was able to answer adequately 20 of the 21 questions, whereas Medline answered only 17 adequately; both databases were required to answer all 21 questions. Articles in Embase are assigned more index terms than those in Medline, and consequently people using Embase may be less likely to miss an important article but must spend more time browsing through irrelevant material.

The overlap of journals in the two databases is only about $34 \%,{ }^{2}$ and other studies have shown that using them both improves the coverage of the literature ${ }^{3-5}$ Despite this, Embase seems to be underused. On the assumption that the words "Embase" and "Medline" would be used in many publications to describe the search strategy, we did a textword search of Medline (1993 to August 1997) and retrieved 66 and 1669 hits respectively.

Our study shows some important differences between the databases. Firstly, although Medline adequately answered most of the questions, a considerable number could be answered only by using Embase. Secondly, Embase complements Medline and vice versa. Finally, to retrieve important articles that are not indexed in Medline it is essential to use Embase in searches done for a comprehensive review or to find rare case reports. Embase is more expensive, more time consuming to use, and perhaps less accessible than Medline. We believe, however, that all practitioners searching for information about drugs and therapeutics should use Embase when Medline has not retrieved sufficient infor- mation or when more comprehensive coverage of the literature is required.

David Woods Lecturer in drug information and clinical pharmacy

Kate Trewheellar Pharmacy student

School of Pharmacy, University of Otago,

PO Box 913, Dunedin, New Zealand

david.woods@stonebow.otago.ac.nz

1 Greenhalgh T. How to read a paper: the Medline database. BMJ 1997;315:180-3. (19 July.)

Smith B, Darzins P, Quinn M, Heller RF. Modern methods of searching the medical literature. Med J Aust 1992; 157:603-11.

3 Odaka T, Nakayama A, Akazawa K, Sakamoto M, Kaka I, Nakayama A, Akazawa K, Sakamoto M, Kinukawa N, Kamakura T, et al. The effect of a multiple litof domain of Japanese life science. J Med Syst 1992;16(4):

4 Biarez O, Sarrut B, Doreau CG, Etienne J. Comparison an evaluation of nine bibliographic databases concerning adverse drug reactions. Drug Intell Clin Pharm 1991; 25:1062-5.

5 Barillot MJ, Sarrut B, Doreau CG. Evaluation of drug interaction citation in nine on-line bibliographic databases. Ann Pharmacother 1997;31:45-9.

\section{What investigations and procedures do patients in hospices want}

\section{Providing ineffective treatment is futile}

EDITOR-In their short report Meystre et al say that "legal advice suggests that if patients request resuscitation it should be provided," referring to our study on the views of elderly patients on cardiopulmonary resuscitation. We contacted the Medical Protection Society and the Medical Defence Union by telephone during our study because a patient in the study who had metastatic lung cancer "demanded" cardiopulmonary resuscitation if he had a cardiac arrest. We were advised that cardiopulmonary resuscitation should be provided if a patient requested it since failure to do so could result in litigation. Subsequently, the Medical Protection Society and the Medical Defence Union said that the advice they had given was specific to the case cited and could not be generalised, and that they would not agree with the assertion "legally if a patient requests cardiopulmonary resuscitation it should be provided." We agree with this as providing treatment that is ineffective is futile.

Cardiopulmonary resuscitation is a useful treatment for some patients. "Do not resuscitate" orders should be made in accordance with the resuscitation policies that all hospitals should have in place. ${ }^{4}$ It may be necessary to include patients in the discussion but it is not appropriate to do so if cardiopulmonary resuscitation is deemed medically futile, unless the patient initiates the discussion. ${ }^{5}$ If a patient requests cardiopulmonary resuscitation when it is inappropriate, discussion must show compassion and reasoning, which requires good communication skills. Doctors must remember that they are under no legal obligation to provide cardiopulmonary resuscitation if patients or relatives demand it. They do, however, have to provide an explanation for their medical decision.

Undergraduate and postgraduate education programmes often omit to teach when and how to discuss cardiopulmonary resuscitation with patients. We have introduced regular tutorials to our preregistration house officers so they can acquire these skills. Unfortunately, the decisions about these procedures are made by more senior doctors, who have often had no experience or training in this field.

Rosemary Morgan Consultant physician in geriatric medicine

Debra King Consultant physician in geriatric medicine Department of Medicine for the Elderly, Wirral Hospital, Upton, Wirral, Merseyside L49 5PE

1 Meystre CJN, Burley NMJ, Ahmedzai S. What investigations and procedures do patients in hospices want? Interview based survey of patients and their nurses. $B M J$ 1997;315:1202-3. (8 November.)

2 Morgan R, King D, Prajapati C, Rowe J. Views of elderly on cardiopulmonary resuscitation. BMJ 1994:308:1677-8

3 Wall JA, Palmer RN. Resuscitation and patients' views. BMJ 1994 JA, Palmer

4 Doyal L, Wilsher D. Withholding cardiopulmonary

resuscitation: proposals for formal guidelines. BMJ resuscitation: propc

5 Stewart K. Discussing cardiopulmonary resuscitation with patients and relatives. Postgrad Med J 1995;71:585-9.

Patients with untreatable cancer almost never survive cardiopulmonary resuscitation

EDitor-Meystre et al say that if terminally ill hospice patients request cardiopulmonary resuscitation then there is a legal obligation to provide it. ${ }^{1}$ They cite a study by Morgan et al to support this view, ${ }^{2}$ and, although Morgan et al were quoted accurately, they themselves had misinterpreted advice which they had been given by the defence organisations. ${ }^{3}$ In subsequent correspondence senior officers of the defence organisations denied that this would be their advice, saying that "it is not correct generally to assert that "legally if a patients requests cardiopulmonary resuscitation it should be provided." "3 They also chastised journal editors for publishing incorrect advice without first checking the source. A more comprehensive search of the literature might have prevented this inaccurate claim being repeated.

Meystre et al's report raises a wider question about the use of cardiopulmonary resuscitation in patients with untreatable cancer. We would be interested to know if the patients interviewed for this survey were told that those with advanced cancer almost never survive resuscitation attempts, ${ }^{4}$ since this information would have been likely to influence their decisions. In our hospital we audited casenotes of all 264 patients having cardiopulmonary resuscitation over 19 months. Twenty eight of these patients survived and were discharged (unpublished data). Twenty of our patients had cancer, and in six it was metastatic. Of the patients with cancer only one, who had non-metastatic disease, survived until hospital discharge, and this patient died in a nursing home four days later. Our local experience is therefore in keeping with previous reports, ${ }^{4}$ and we regard advanced cancer as a condition for which resuscitation is futile.

Patients entering hospice care are usually not going to benefit from attempts at curative surgery, which is, correctly, not 
offered as a treatment option. The same principle applies to cardiopulmonary resuscitation. Doctors have neither a moral nor a legal obligation to offer treatment that is ineffective, ${ }^{5}$ even if it is requested by patients.

Kevin Stewart Consultant physician

Mike Bacon Specialist registrar

Department of Medicine and Elderly Care, Royal

Hampshire County Hospital, Winchester

SO22 5DG

Lesley Bowker Senior registrar

Radcliffe Infirmary, Oxford OX2 6HE

Meystre CJN, Burley NMJ, Ahmedzai S. What investigations and procedures do patients in hospices want? Interview based survey of patients and their nurses. BMI 1997.315:1202-3 (8 Natients

2 Morgan R, King D, Prajapati C, Rowe J. Views of elderly patients and their relatives on cardiopulmonary resuscitapatients and their relatives

3 Wall JA, Palmer RN. Resuscitation and patients' views. $B M J$ 1994;309:1442-3.

4 O'Keeffe S, Ebell MH. Prediction of failure to survive following in-hospital cardiopulmonary resuscitation: comparison of two predictive instruments. Resuscitation $1994 ; 28: 21-5$.

5 Doyal L, Wilsher D. Withholding and withdrawing life sustaining treatment from elderly people: towards forma guidelines. BMJ 1994;308:1689-92.

\section{Doctors are under no legal obligation to} provide ineffective treatment

EDITOR-Meystre et al report that patients who are terminally ill are prepared to accept invasive procedures more readily than their nurses are. ${ }^{1}$ The article points out that care must be taken to ensure that patients are not denied the opportunity of therapeutic interventions because of staff attitudes, but I think several of Meystre et al's conclusions are misleading.

I believe that the difference in attitudes exists not because nurses wish to deny their patients benefit from treatment but because nurses are more aware of the true-and limited-benefit of some of the interventions proposed. To ask a patient with advanced cancer "If your heart stopped unexpectedly would you want to be resuscitated?" without explaining the likely outcome of that resuscitation does not provide useful information. It has been shown that patients acquire their knowledge of cardiopulmonary resuscitation predominantly from television and that most patients think that it is "a mostly successful procedure." ${ }^{3}$ Studies have shown, however, that cardiopulmonary resuscitation of patients with advanced malignancy almost invariably fails to re-establish cardiopulmonary function. At best it succeeds only to result in further cardiopulmonary arrest with no intervening hospital discharge. ${ }^{4}$ It is therefore inappropriate in most of the hospice population.

Cardiopulmonary resuscitation is the most extreme example of the interventions proposed. Other questions in the survey were biased by the preface that medical staff thought that a particular intervention would improve the patients' care. The article does not say whether the patients were given any indication of the nature or degree of that improvement. The nursing staff would certainly have had that knowledge when answering the same questions.

In response to Meystre et al's concluding paragraph I would emphasise that equal care must be taken not to subject patients to interventions of negligible or limited benefit on the basis of poorly informed choices made by them.

Valerie O' Donnell Senior registrar in palliative medicine

Aintree Palliative Care Team, Fazakerley Hospital, Liverpool L9 7AL

1 Meystre CJN, Burley NMJ, Ahmedzai S. What investigations and procedures do patients in hospices want? Interview based survey of patients and their nurses. $B M$ 1997;315:1202-3. (8 November.)

2 Liddle J, Gilleard C, Neil A. The views of elderly patient and their relatives on cardiopulmonary resuscitation. $J R$ Coll Physicians 1994;28:228-9.

3 Mead JE, Turnbull C. CPR in the elderly: patients' and relatives' views. J Med Ethics 1995;2 1:39-44.

4 Faber-Langendon K. Resuscitation of patients with metastatic cancer. Is transient benefit still futile? Arch Intern Med 1991;151:235-9.

\section{Questions to patients and nurses should have been identical}

EDITOR-Meystre et al compared answers on the acceptability of invasive procedures and treatments given by patients with cancer with answers given by their nurses. ${ }^{1}$ We need to be much more aware of the different perspectives of clinicians and patients, particularly when we consider how, and by whom, difficult choices and decisions about treatment should be made.

A flaw in the study, however, makes it difficult to draw useful conclusions from the findings. The patients and nurses were not asked the same questions, and so their answers cannot be compared meaningfully. Patients were asked to rate how much they would want procedures that staff thought would help to improve their care. Nurses were asked to rate how appropriate it would be to carry out the procedures. These are quite different considerations, which reflect the distanced position held by professionals in the the healthcare system-a position that requires impartiality and a recognition of reasonable limits-and the immediacy of the individual patient's predicament-which means partiality and a concern that someone will go to any lengths on the patient's behalf.

The views of nurses and patients on the acceptability of procedures might have been less divergent if they had been asked the same questions, and even less so if the questions had been reversed. Nurses may want to do all (if it were possible) that could be done to improve patient care, while patients may acknowledge (with regret) the constraints imposed by their illness and by the clinical context.

Gilligan differentiated ethic of justice from the ethics of care. ${ }^{2}$ In accordance with this, further research and clinical practice should take into account the differing ethical stances of those with greater and those with lesser power in the clinical situation.

Annie Mitchell Lecturer in clinical and community psychology.

Department of Psychology, University of Exeter, Washington Singer Laboratories, Exeter EX4 4QG

1 Meystre CJN, Burley NMJ, Ahmedzai S. What investigations and procedures do patients in hospices want? Interview based survey of patients and their nurses. $B M$ 1997;315:1202-3. (8 November.)

2 Gilligan C. In a different voice:psychological theory and women's development. Boston, MA: Harvard University Press, 1982.

\section{Responses are not comparing like with}

EDITOR-Meystre et al investigated the attitudes of terminally ill patients in a hospice towards investigations and procedures. ${ }^{1}$ I am concerned about the validity of their results.

The responses from the nurses may well have been influenced by their professional knowledge. Most medical and nursing professionals would agree to any investigation if it were "thought necessary for the medical management of their patient." I therefore think that in fact the nurses were answering the question "How appropriate do you feel it would be to carry out these investigations?"

Patients who were offered investigations or treatment that were thought necessary for the medical management of their disease would clearly be more likely to consent to them. The responses are therefore not comparing like with like.

\section{Charles Daniels Macmillan consultant in palliative} care

Graig Gannon consultant in palliative care Macmillan Team, Hounlow and Spelthorn Community and Mental Health NHS Trust, West Middlesex Hospital, Isleworth, Middlesex TW7 6AF

1 Meystre CJN, Burley NMJ, Ahmedzai S. What investigations and procedures do patients in hospices want? Interview based survey of patients and their nurses. $B M J$ 1997:315:1202-3. (8 November.)

\section{Authors' reply}

EDITOR-Morgan and King pointed out that we were wrong ${ }^{1}$ and there is not always a legal obligation to provide cardiopulmonary resuscitation if a patient requests it, and we agree with Stewart et al that cardiopulmonary resuscitation in patients with advanced cancer is usually futile.

Patients were given brief descriptions of each option available, and for cardiopulmonary resuscitation this included "Resuscitation involves calling two or three doctors urgently ... laying a patient flat, using a bag and a mask applied closely to the face, ... pressing down hard rhythmically on the chest.... A drip is put up and drugs injected ... the breathing mask would be replaced by a tube down into the lungs.. . . Attempts at resuscitation are not very successful but the outcome depends on how ill the person is before the heart stops and how quickly resuscitation can be started." We believe this is even handed and not overoptimistic.

The comments on the futility of cardiopulmonary resuscitation are based on the assumption that all hospice patients with cancer are irreversibly near death. Many hospices take patients earlier in the course of their disease and offer more invasive medical interventions, such as endoscopy, paracentesis, or spinal analgesia. Some of these patients may be put at risk of sudden cardiac arrest, and it seems reasonable to offer cardiopulmonary resuscitation to those whose life expectancy otherwise could be several months.

We did not ask patients and nurses exactly the same question because we were not measuring whether nurses knew what 
their patients would say (as we did regarding performance status) but how far nursing was influenced by patient autonomy. Therefore, we asked to what extent, if "we thought it would improve your care," individual patients would give consent. A nurse who knew the patient well was asked "How appropriate do you think it would be to do the following tests if the need arose during the management of your patient?" The lack of agreement on eight of 14 issues (the nurses always scored below the patients) may show, as Daniels says, that "the nurses may well have been biased by their professional knowledge." It would be a pity if the autonomy of patients, freed from the "paternalism" of an earlier generation of doctors, was limited by the "maternalistic" bias of well meaning nurses, making demedicalised care the only option when patients themselves would opt for intervention. We would welcome larger, preferably multicentre, studies to confirm or refute these findings.

Chantal Meystre Consultant in palliative medicine Mary Ann Evans Hospice, George Eliot Hospital, Nuneaton CV10 7DJ

Neil M J Burley Senior house officer psychiatr St Michael's Hospital, Warwick, CV34 5QW

Sam Ahmedzai Professor of palliative medicine, Department of Surgical and Anaesthetic Sciences, University of Sheffield, Royal Hallamshire Hospital, S10 2JF

1 Ahmedzai S, Mallett K. Brooks D, Johnson IS. What do hospices do? (abstract). Palliat Med 1997;11:69-70

\section{Culyer reforms will create new opportunities for research}

EDITOR-The role of director of research and development in a teaching hospital is a challenging one, particularly during the introduction of the Culyer reforms. It does not include discouraging clinical staff who are industrious in their service work, enjoy teaching, and are active in research from continuing to develop evidence that can lead to improved clinical practice. ${ }^{1}$ Trusts that wanted to obtain money from the levy fund that was established to support research and development had to satisfy the NHS Executive that they would, firstly, implement a corporate research strategy; secondly, prospectively review the quality of proposed studies; thirdly, rigorously manage support costs for research; and, fourthly, encourage but not subsidise commercial research. These obligations are the result of a major evidence based reform of NHS finance and translate directly into the messages from the author's anonymous director of research and development that were quoted in the article.

Under the new support arrangements for research, clinicians are subject to a higher level of research management, and their projects, properly peer reviewed and costed, must be placed in a coherent strategic framework. These changes are deemed to be inimical to clinical research, but is this true? By rising to this challenge we were able to put forward a competitive bid for levy funds. Its success will allow us to strengthen the research support that is available to our clinical researchers, thereby enhancing their ability to compete for grant funding and further improving the high quality of their research output.

Although consultants in this trust think that applying for grants is futile and believe that funding bodies favour basic science, the evidence contradicts this. Many sponsors fund research into health services and assessment of health technology across the range of clinical specialties. Successful applicants show that authoritative proposals can be put forward in any area of health care. Satisfactory scientific peer review should be a precondition for ethical approval.

The Culyer reforms will clarify how NHS resources support research and development, improve value for money, and widen participation in clinical research. Some clinicians, whose pilot studies are never followed up and whose substantive studies are too small to inform clinical practice or unnecessarily duplicate earlier work, will feel discouraged by the new environment in clinical research. They will probably be unwilling to change their established pattern of research and will therefore not come within the new support framework. I believe, however, that most will welcome the opportunities created by a system that forces researchers to articulate their research plans explicitly, encourages multicentred and multidisciplinary studies, and demands that fellow professionals respond to rigorous evidence.

Clark Lewis Director of research and development King's College Hospital, London SE5 9RS

1 Conflict [personal view]. BMJ 1998;316:80-1. (3 January.)

\section{Clinician scientists face difficult future}

EDITOR-Bitter criticism has been levelled at the Calman changes, ${ }^{1}$ but nothing has been said of the 100 or so people in Britain who hold clinician scientist fellowships. ${ }^{2}$ Only four funding bodies award these fellowships: the Medical Research Council, Wellcome Trust, British Heart Foundation, and Cancer Research Campaign. Together they provide around $£ 30$ million of support for these individuals. The success rate for applicants in these competitive fellowships is consistently only $25 \%$. These awards, universally regarded as successful and cost effective, provide for three to seven years of personal funding. Holders of the awards ultimately progress to senior fellowships or full faculty positions.

The Calman changes have introduced a rigid system requiring these individuals to fulfil inflexible criteria; the changes take no account of the fact that they ultimately will be engaged principally in research, providing only a minimal, and often superspecialty, clinical service. The absurdity of this situation is that clinician scientists could spend six years (after obtaining the MRCP) in research, followed by a further four to five years in full time clinical training. Worse still, they spend part of their week on the wards and part on the bench, achieving neither intended goal satisfactorily.

As Calman deserts a sinking academic ship for greener pastures, those he leaves behind may begin to wonder what, if any, future there is in pursuing an academic career in the United Kingdom. The funding bodies are trying to be as flexible as possible, while others apply pressure on the committees that award specialist certificates. But this is not a time for quiet diplomacy. Two of the four funding bodies are already concerned about the reduction of inquiries about these fellowships (personal communication), and some award holders are thinking about withdrawing from awards already obtained in order to return to the NHS to fulfil clinical requirements-a damning indictment against the Calman changes.

So what is to be done? Clinician scientists should automatically be awarded with a training number in the specialty of their choice, ${ }^{3}$ and trusts should be required to develop fast track training programmes sufficient for accreditation. Postgraduate deans, who have their own interpretation of the rules as applied to academics, seem to be party to unfair regional discrepancies; some seem to be more accommodating than others. They not only have the power to help these individuals but a duty and responsibility to do so. If clinician scientists cannot be given latitude in the new system then no one is safe.

Pankaj Sharma BHF clinician scientist Clinical Pharmacology Unit, University of Cambridge, Addenbrooke's Hospital, Cambridge CB2 2QQ 1 Barber P. The colleges, Calman, and the new deal. Lancet
1997;350:974.
2 Chaudhry B, Winyard P, Cale C. Academia: the view from
below. BMJ 1997;315:560-1.
3 College of Vice Chancellors and Principals. Clinical
academic careers. Report of an independent task force. London:
CVCP, 1997.

\section{Early discharge after stroke}

\section{Use of Barthel index was not appropriate}

EDITOR-There are three reasons why Rudd et al may be at fault when they conclude that early discharge of patients with stroke has no clinical importance.

Firstly, the authors used the Barthe index as the main outcome measure. This scale is insensitive to change at higher scores. ${ }^{2}$ More than 1 in 10 of the patients had a maximum Barthel score at randomisation, and improvement therefore cannot be shown in these patients with this index. The study was powered to detect a 3.5 point difference in the Barthel index. To be able to detect such a difference, the Barthel score should have been $\leqslant 16.5$ at the start of the study. Only about two thirds of the patients, however, seem to have had this low score, so a difference of this magnitude is unlikely to have occurred. Moreover, the most probable 
effects of early discharge are on the psychosocial level ${ }^{3}$ and thus are not measured by the index.

Secondly, outcomes were assessed after one year. Most functional improvement after stroke takes place during the first few months. ${ }^{4}$ Different treatment strategies may influence the speed of this, and such effects may be clinically important even if they disappear within a year.

Thirdly, nearly two weeks elapsed before half the patients had been randomised, and some were not randomised until considerably later. Thus the authors had no opportunity to start the intervention-that is, prepare for early discharge-during the first important weeks. ${ }^{5}$

The study provides important though insufficient information for clear conclusions to be drawn on the role of early discharge. Such conclusions should preferably be based on several studies with common, appropriate outcome measures. ${ }^{5}$

Torgeir Bruun Wyller Research fellow Department of Geriatric Medicine, Ullevaal Hospital, N-0407 Oslo

1 Rudd AG, Wolfe CDA, Tilling K, Beech R. Randomised controlled trial to evaluate early discharge scheme for patients with stroke. BMJ 1997:315:1039-44. (25 October.)

2 Wellwood I, Dennis MS, Warlow CP. A comparison of the Barthel index and the OPCS disability instrument used to Bisability instrument used to 1995;24:54-7.

Seale C, Davies P. Outcome measurement in stroke rehabilitation research. Int Disabil Studies 1987:9:155-60.

4 Jørgensen HS, Nakayama H, Raaschou HO, Vive-Larsen J, Støier M, Olsen TS. Outcome and time course of recovery Støier M, Olsen TS. Outcome and time course of recovery
in stroke. Part II. Time course of recovery. The in stroke. Part II. Time course of recovery. The
Copenhagen stroke study. Arch Phys Med Rehabil

Copenhagen stroke study. Arch Phys Med Rehabil
1995;76:406-12.
5 Rodgers H, Soutter J, Kaiser W, Pearson P, Dobson R, Skil-

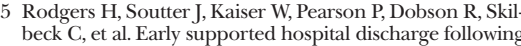
acute stroke: pilot study results. Clin Rehabil 1997;11:280-7.

\section{Authors' reply}

Editor-We agree that the Barthel index has considerable limitations as an outcome measure for stroke. We chose it because it is the most widely used outcome measure in comparable trials and because high completion rates are attainable, with results being valid whether it is completed by the patients, carers, or researchers. We were seeking to detect a group difference of 3.5 points on the Barthel index rather than this difference in each individual. The intervention was aimed primarily at physical rather than psychosocial rehabilitation, and we therefore expected that this would be reflected in the outcomes. Nevertheless, we measured a wide range of outcomes, including those covering psychosocial function, none of which showed significant differences between the two groups.

We chose one year as the key outcome point, arguing that sustained rather than transient effects were more important to achieve. Outcomes were measured at two, four, and six months; preliminary analysis of these showed no significant differences between the groups, even in the early phases of recovery.

Within a trial setting it would not have been feasible to prepare patients for early discharge when half of them would subse- quently end up receiving conventional care. We accept that greater benefits could potentially have been achieved, particularly in length of stay, if the patients had not had to wait to reach the randomisation points before discharge was planned.

As this is the first full trial report on early discharge after stroke we must wait for reports of other trials in which similar outcome measures are used. These could then be combined to answer other key questions, such as the role of early discharge for different subgroups of patients.

Anthony Rudd Consultant physician

Elderly Care Unit, Guy's and St Thomas's NHS Trust, London SE1 7EH

Charles Wolfe Senior lecturer

Department of Public Health, UMDS, St Thomas's Hospital, London SE1 7EH

Kate Tilling Lecturer

Roger Beech Senior research fellow

Centre for Health Planning and Management,

Keele University, Keele, Staffordshire ST5 5BG

\section{Basing resource allocation formulas on standardised mortality ratios would be wrong}

EDITOR-Sheldon proposes that resource allocation formulas should revert to the methods proposed by the resource allocation working party over 20 years ago. ${ }^{1} \mathrm{He}$ thinks that instead of messing around with complicated statistics we should use the standardised mortality ratio (although he does not specify which variant $\left.{ }^{2}\right)$. It is an appealing simplification, but it won't do for four reasons.

Firstly, because allocations are having to be made to much smaller populations, we need accurate and robust formulas and guidance on where discretion is appropriate and what the likely sources of bias are; rough approximations are worse than useless.

Secondly, up to date measures are required. Although standardised mortality ratios can be calculated annually, most of the deaths concerned-except for a small number of accidental and avoidable deaths ${ }^{3}$-are a culmination of vulnerability over a long period. Annual movements probably reflect more the transient pattern of migration of elderly people than changes in underlying social conditions. Whatever the arguments in favour of "making do" with standardised mortality ratios as an alternative to proxies for material deprivation based on the census, the ratios seem unlikely to be more than a poor substitute for direct measures of poverty (such as uptake of benefits) that are now becoming available. ${ }^{4}$

Thirdly, the presumption that the standardised mortality ratio is the best all round proxy is based on the view that it reflects the bundle of factors that lead to use of health services. But if there is one thing that has been learnt over the past 15 years about whether inequalities in health between social classes have increased, it is that arguments phrased in terms of overall death rates are of little value, because different components of the standardised mortality ratio have different aetiologies. ${ }^{5}$

Fourthly, resorting simply to the standardised mortality ratio means excluding the possibility that material deprivation influences use of health services other than through the impact it makes on morbidity and mortality.

Twenty years ago most deaths were related to poverty so that an overall index more or less reflected the distribution of poverty in a population. ${ }^{5}$ Nowadays the standardised mortality ratio reflects a mix of often contradictory tendencies in terms of living standards and diseases related to lifestyle. Knowing an area's standardised mortality ratio tells us much less than it used to. Statements about the best way to approach resource allocation should be based on evidence, not just on appeals to simplicity.

Roy A Carr-Hill Senior research fellow

Centre for Health Economics, York University, York YO1 5DD

James Q Jamison Director

Health and Health Care Research Unit, Queen's

University of Belfast, Belfast BT12 6B

1 Sheldon TA. Formula fever: allocating resources in the NHS. BMJ 1997;315:964. (18 October.)

2 Carstairs V, Morris R. Deprivation and health in Scotland. Aberdeen: Aberdeen University Press, 1991.

3 Charlton JRH, Hartley RM, Silver R, Holland WW. Geographical variation in mortality from conditions amenable to intervention in England and Wales. Lancet 1983;i:691-6.

4 Jamison J, O'Reilly D, Steveson M, Reid J, Merriman B, Carr-Hill RA. A model to predict acute hospital utilisation uptake of social security benefits and low birth weight [abstract]. J Epidemiol Community Health 1997;51:600.

5 Illsely R, Baker D. Inequalities in health: adapting the theory to fit the D. Inequalities in health: adapting the theory to fit the facts. Bath: University of Bath, 1997. (Social
policy papers No 26.)

\section{Are part time doctors better doctors?}

\section{Doctors need flexible training and flexible jobs}

EDITOR-Gibson raised some serious points for further discussion about part time working in career grades. ${ }^{1}$ Kumar contributes nothing to an informed debate on this topic, and his argument runs counter to the views of respected national bodies such as the Royal College of Physicians. ${ }^{2}$ He states: "Part timers are no good for any medical specialty where there may be a need for quick action... ." He says that he works 50 hours of the 168 in a week. This means that, for the remaining 118 hours, someone from his team has to be available, or there is no one to undertake the responsibilities. A team provides continuity of service to patients, and part timers can be highly effective members of a team

Overall, some $8 \%$ of specialist registrars are training on a flexible basis; in Oxford, Kumar's region, this proportion is $15.3 \%$ (Department of Health, annual medical workforce census). It is therefore unfortunate that he should seek a confrontation at the very time when flexible and full time training are so much more closely inte- 
grated and flexible training leads successfully to consultant posts. The same constraints that lead doctors to ask for flexible training are often still present when they seek a career grade post, and these doctors will seek part time consultant posts.

In some specialties, including general practice, the shortage of doctors to deliver the service is severe. We need to facilitate training and career grade opportunities for young doctors who might otherwise leave, temporarily or permanently, by providing flexible (part time) opportunities. As Allen says: “... a radical assessment is needed of how we are to make use of the talents of the brightest and best of successive generations of young people who enter medicine. Assumptions still predicated on a medical workforce made up of men working full time mainly in one specialty for 40 years are hopelessly misguided... ."3

Ilfra Goldberg Associate dean, postgraduate medicine, Thames Region

Ri Hornung Dean of postgraduate general practice, South Thames

Thames Postgraduate Medical and Dental Education, University of London, London WC1N 3E]

1 Gibson H. Are part time doctors better doctors? [Caree focus]. BMJ 1997;315 (classified supplement):2-3. (11 October.)

2 Kumar V. Full time backlash? [Career focus]. BMJ 1997;315 (classified supplement):3. (6 December.)

3 Allen I. Career preferences of doctors. BMJ 1996;313:2.

\section{Service depends on teamwork}

EDITOR-Kumar seems to think he can personally provide continuity of care while he is only working 50 hours a week. ${ }^{1}$ Who manages his patients when they are ill during the remaining 118 hours? No individual doctor, full or part time, can be available for all the hours their patients may need them. A continuous service depends on a team of health professionals working together and communicating effectively, whether or not their consultant is present. Perhaps the wisdom that part time doctors acquire during their "non-working" hours is the realisation that they are not indispensable but part of a team, both at work and at home.

Anna Lipp Senior registrar in anaesthetics Norfolk and Norwich Hospital, Norwich NR1 3SR

1 Kumar V. Full time backlash? [Career focus]. BM] 1997;315 (classified supplement):3. (6 December.)

\section{Fulfilled doctors are better doctors}

EDIToR-The London initiative zone educational incentives programme (LIZEI) is using education as an incentive to attract general practitioners to enter, stay in, or return to, general practice in inner cities. The essence of the programme's approach is flexibility. Providing opportunities for doctors to develop their skills and interests enhances their enjoyment, and thus the quality, of their work.

Kumar obviously disagrees. ${ }^{1}$ The number of hours a doctor spends in contact with patients, rather than the quality of work done within those hours, seems to be the issue for him. Continuity of care is important and cannot be maintained if a doctor is not available for a sufficient number of hours. It is simply not true, however, that someone who has gone through medical training while giving low priority to other aspects of his or her personal development is therefore a better doctor. As Gibson argued, the opposite is usually the case. ${ }^{2}$

Patients benefit from having doctors who are fulfilled in their personal lives. Would Kumar suggest that children of doctors remain relatively unparented, or would he prefer medicine to return to being the exclusive domain of men? He failed to mention who looks after his children while he is pursuing his many, varied, and time consuming activities.

One of us (CS-V) is a mature medical student, and the other (LM) is completing a year as a returner in general practice. We both have children and have both explored other interests before settling on our career paths. We are both sure that we are doing what we are doing-combining work and family-because we want to and not because we are fulfilling the expectations of others. We noted with interest that, in the survey reported recently in Career focus, 95\% of medical students considered flexible training a good idea. ${ }^{3}$

A scheme proposed at Guy's and St Thomas's Hospitals offers students leaving school and selected for admission to medical school a place which would then be kept for them until they were 21 years old. In the intervening time, they would be encouraged to pursue their own interests with a place guaranteed at the end. In case they realised during that time that medicine was not for them, they could withdraw with no recrimination. This is an excellent proposal.

Doctors have the same needs as anyone else to be good parents and fulfilled people. If a lack of flexibility in working practices and attitudes does not allow these needs to be expressed, doctors, and consequently patients, will suffer.

Cynthia Sahleen-Veasey Medical student

King's College Medical School, Weston Education Centre, London SE5 7DF

Lesley Morrison General practitioner

Goodinge Health Centre, London N7 9EW

1 Kumar V. Full time backlash? [Career focus]. BMJ 1997:315 (classified supplement):3. (6 December)

2 Gibson H. Are part time doctors better doctors? [Caree focus]. BMJ 1997;315 (classified supplement):2-3. (11 October)

3 Sinha A, Cook A. What do medical students think of flexible training? BMJ 1997;315 (classified supplement):2-3 (6 December.)

\section{Continuity of care is likely to suffer}

EDITOR-Kumar says that his comments may not be applicable universally. ${ }^{1}$ There is no doubt in my mind that the strongest feature of British primary care has been its intention and often its ability to provide continuity of patient care. This is now being undermined as low morale, exhaustion, and frustration sap the patience of many. Canaries taken by miners down the pit quickly detected poor air quality, and, similarly, the most sensitive and creative people in today's work environments are often the first to start wilting. I know many practices that are now surviving on the backs of the booming locum industry-a phenomenon also repeated in the teaching and nursing professions.

The increases in numbers of job sharers and "portfolio practitioners" may be good for the health of the particular people, but they are going to make it much harder for those left in the job to ensure continuity. If the people of Britain think that it is difficult to see the same doctor more than oncethey haven't seen anything yet.

Chris Manning General practitioner

St John's Health Centre, Twickenham TW11 9HG

1 Kumar V. Full time backlash? [Career focus]. BMJ 1997;315 (classified supplement):3. (6 December)

**We received eight other letters, six of them from doctors working flexibly. They all agree that "part time" merely describes the way that all doctors work, to a greater or lesser degree. The debate should consequently not be about whether part time or full time is better, but how flexible training and work patterns can be developed that accommodate different doctors' different needs in a changing society, and therefore offer patients better care and greater continuity.

\section{More patients should be excluded from being tissue donors}

EDitor-In their editorial, Allan and Tuft note the United Kingdom's criteria aimed at preventing patients with Creutzfeldt-Jakob disease from becoming corneal donors. ${ }^{1}$ In the United Kingdom, as elsewhere, discrepancies occur in practice between groups excluded as blood donors and as corneal (and other) graft donors. Among these discrepancies is the fact that relatives of patients with Creutzfeldt-Jakob disease are excluded from donating blood but not necessarily corneas. Asymptomatic relatives of the $10-15 \%$ of patients with hereditary Creutzfeldt-Jakob disease (which often occurs without a clear family history) may share the same dominant genetic defect and have a theoretical potential for transmitting the disease in the presymptomatic stage of their illness.

We recommend that blood relatives of patients with Creutzfeldt-Jakob disease or the related hereditary conditions GerstmannSträussler-Scheinker disease and fatal familial insomnia should be added to the list of those excluded as corneal donors. Ideally, it would be advisable to ensure the absence of Creutzfeldt-Jakob disease by histological examination of a small piece of frontotemporal cortex from any cadaver used as a source of tissue grafts (a requirement soon to be enacted for dura mater grafts in the United States, according to the transcript of the meeting of the transmissible spongiform encephalopathy advisory committee on 6 October 1997). However, the large number of corneal transplant operations that are performed each year, coupled with the 
exceptional rarity of recognised transmission of Creutzfeldt-Jakob disease from contaminated grafts, make this proposal a legitimate subject for argument.

Martin Zeidler Specialist registrar in neurology Western General Hospital, Edinburgh EH4 2XU

Paul Brown Senior research scientist

Laboratory of Central Nervous System Studies, National Institute of Neurological Disorders and Stroke, National Institutes of Health, Bethesda MD 20892, USA

1 Allan B, Tuft S. Transmission of Creutzfeldt-Jakob disease in corneal grafts. BMJ 1997;315:1553-4. (13 December.)

\section{Acute excited states and sudden death}

\section{Death after restraint can be avoided}

EDITOR-Farnham and Kennedy's recent editorial on sudden death in patients with acute psychiatric illness ${ }^{1}$ who are being restrained does not reflect the forensic literature fairly. It omits evidence from key publications $s^{23}$ and twice misattributes statements to a paper that specifically excluded such deaths from the reported study. ${ }^{4}$

The current consensus on "restraint asphyxiation" is reflected in a guidance statement of the United States Department of Justice. ${ }^{5}$ Any person who is restrained prone has trouble breathing when pressure is applied to his or her back or when handcuffed and "hog tied," ${ }^{3}$ and obesity exacerbates this. People's natural reaction is to struggle more violently, which may be met with still more restraining force, resulting in greater oxygen deficiency and, in some cases, death. Risk factors include any condition, such as ischaemic heart disease or excited delirium, ${ }^{2}$ that increases susceptibility to cardiac arrhythmias, as well as intoxication with alcohol or drugs.

Recommendations given to police officers on how to prevent such deaths include releasing people from the prone position as soon as they are handcuffed, not sitting on them, and never tying handcuffs to a leg or ankle restraint (hog tying). ${ }^{5} \mathrm{~A}$ form of hog tying restraint known as the police leg lock was prohibited in Denmark in 1994, after a campaign by the human rights organisation Amnesty International when an incident had left an 18 year old permanently brain damaged. There is evidence that restraint procedures that compromise respiratory movements are potentially dangerous, and this needs to be taken into account in any debate on their use in a healthcare setting.

Derrick Pounder Professor of forensic medicine Department of Forensic Medicine, University of Dundee, Royal Infirmary, Dundee DD1 9ND

1 Farnham FR, Kennedy HG. Acute excited states and sudden death. BMJ 1997;315:1107-8. (1 November.)

2 O'Halloran RL, Lewman LV. Restraint asphyxiation in excited delirium. Am J Forensic Med Pathol 1993;14:289-95.

3 Reay DT, Fligner CL, Stilwell AD, Arnold J. Positional asphyxia during law enforcement transport. Am J Forensic Med Pathol 1992;13:90-7.

4 Bell MD, Rao VJ, Wetli CV, Rodriguez RN. Positional asphyxiation in adults. Am J Forensic Med Pathol 1992;13:101-7.

5 Department of Justice. Positional asphyxia-sudden death Rockville, MD: National Institute of Justice, 1995. (National Law Enforcement Technology Center Bulletin.)
Acute excited states are not caused by high blood concentrations of cocaine

EDITOR-Much more is known about acute excited states and sudden death than Farnham and Kennedy's editorial suggests. ${ }^{1}$ Such states are not, as they say, commonly associated with high blood concentrations of cocaine-subjects do not have high concentrations of cocaine. In 45 cases in Miami, concentrations were similar to those seen in asymptomatic recreational users. ${ }^{2}$ In people whose deaths are related to cocaine, whether due to psychosis or not, blood concentrations completely overlap those of people whose death was from trauma with cocaine as an incidental finding. ${ }^{3}$

Neurochemical abnormalities have been identified. There are fewer $D_{2}$ receptors in the centres of the hypothalamus that oppose $\mathrm{D}_{1}$ mediated temperature increases. ${ }^{4}$ This explains why those who die are invariably hyperthermic. In the series from Miami, mean body temperature was $40.6^{\circ} \mathrm{C}$ at the time of the first medical examination. Changes induced by cocaine in the number and distribution of $\kappa_{2}$ opiate receptors within the amygdala may explain the distinctive psychotic symptoms and violent agitation. ${ }^{5}$ These changes can be shown at any neurochemistry reference laboratory, provided the brain is removed and slices frozen within 12 hours. The mere presence of these changes does not prove that police misconduct or medical mismanagement did not occur, but it does prove that the patient had a disease that is usually fatal.

Death is often attributed to capsicum (pepper spray) poisoning rather than to the underlying psychiatric state. In trying to spray agitated psychotic people, police officers often miss their face and spray their back or shoulder and sometimes the faces of other officers. We use saline swabs to recover capsicum from skin and clothing of people who are alive and methanol to recover it from those who have died. There are no assays for capsicum in biological matrices, but toxicity is effectively ruled out if capsicum cannot be recovered from the facial area.

Prudent management also includes a meticulous, well photographed, neck dissection to rule out neck compression, and measurement of drug concentrations in the brain. These seem to provide an accurate picture of the pattern of cocaine use, and the use at the time of death, whereas blood measurements are often unreliable.

Finally, protocols must be put in place to ensure that all the appropriate measures are immediately taken. These are high profile cases. Since "popular journalism favours controversy and blame rather than balance and exploration," it is probably a good idea to implement such protocols before the backlog of cases gets too large.

Steven B Karch Assistant medical examiner Boyd G Stephens Chief medical examiner City and County of San Francisco, Hall of Justice, San Francisco, California CA94103, USA
1 Farnham FR, Kennedy HG. Acute excited states and sudden death. BMJ 1997;315:1107-8. (1 November.)

2 Wetli C, Mash D, Karch, S. Cocaine-associated agitated delirium and the neuroleptic malignant syndrome. $A m J$ Emerg Med 1996;14:425-8.

3 Karch S, Stephens B, Ho CH. Relating cocaine blood levels to toxicity-an autopsy study of 99 cases. J Forensic Sci (in press.)

4 Staley J, Hearn L, Ruttenber A, Mash D. High affinity cocaine recognition sites on the dopamine transporter are elevated in fatal cocaine overdose victims.J Pharmacol Exp Ther 1994;271:1678-85.

5 Staley J, Rothman R, Rice K, Partilla J, Mash D. K2 opioid receptors in limbic areas of human brain are up regulated by cocaine in fatal overdose victims. 1997;17:8225-33.

\section{Many third molar teeth are probably removed unnecessarily in Sandwell}

Editor-Jones et al report their interview study to assess dentists' agreement on the treatment of asymptomatic impacted third molar teeth. ${ }^{1}$ They state that a quarter of these teeth are removed without being diseased, and give as a reference for this statement a paper by colleagues and myself; in fact the figure was half, not a quarter. ${ }^{2}$

It is reassuring to see that Jones et al used as the gold standard guidelines that had been outlined at a consensus development conference of the National Institutes of Health. Their findings are alarming but not unexpected. The purchasers for Birmingham have prepared guidelines for third molar surgery largely based on the consensus guidelines. This document, however, still says that impacted third molars can be removed "on the decision of a consultant"-in other words, without any clinical basis that can be justified.

The increase in the number of third molars being extracted by general dental practitioners is alarming. In Sandwell (adjacent to Birmingham) during 1994-5 the ratio of the actual to expected episodes of hospital extraction of third molars was the second lowest in the West Midlands region. ${ }^{3}$ Even more worrying, however, is the fact that the number of claims per thousand population aged 15-39 made by dentists in Sandwell for the removal of third molars in 1994-5 was the highest in the West Midlands. ${ }^{3}$ If the dentists in Sandwell have the same attitudes as those in the study group then I suspect that many third molars are removed unnecessarily. The challenge is for the Dental Practice Board to monitor and audit this, and for the profession to bring about pressure to stop such activity.

Victor Lopes Senior house officer, surgical rotation City Hospital, Birmingham B18 7QH

1 Jones CM, O'Brien K, Blinkhorn AS, Rood JP. Dentists' agreement on treatment of asymptomatic impacted thir molar teeth: interview study BMJ 1997.315:1204. (8 November.)

2 Lopes V, Mumenya R, Feinmann C, Harris M. Third molar surgery: an audit of the indications for surgery, post-operative complaints and patient satisfaction. $\mathrm{Br} J$ Oral Maxillofac Surg 1995;33:33-5.

3 Taylor K, Elley K. Improving oral health in Sandwell. West Bromwich: Department of Public Health, Sandwell Health Authority, 1997. 